13 O'Connor DW, Pollitt PA, Hyde JB, Fellowes JF, Miller ND, Roth M. A follow-up study of dementia diagnosed in the community using the Cambridge mental disorders of the elderly examination. Acta Psychiar Cambridge mental

14 O'Connor DW, Pollitt PA, Brook CPB, Reiss BB. The validity of informant histories in a community study of dementia. International fournal of Geriatric Psychiatry 1989;4:203-8.

15 O'Connor DW, Pollitt PA, Brook CPB, Reiss BB. The distribution of services to demented elderly people living in the community. International goumal of Geriatric Pychiory $1989,4: 339$ in

16 Branch LG, Jette AM. A prospective study of long-term care and inștitution alization among the aged. Am F Public Health 1982;72:1373-9.
17 Boas JW, Haybittle JL, Fowler JF, Emery EW. The number of patients required in a clinical trial. Brf Radiol 1971;44:122-5.

8 Pollitt PA, O'Connor DW, Anderson I. Mild dementia: perceptions and problems. Ageing and Society 1989;9:261-75

19 O'Connor DW, Pollitt PA, Roth M, Brook CPB, Reiss BB. Problems reported by relatives in a community study of dementia. Br F Psychiatry 1990;156: $835-41$

20 Gilleard CJ. Living with dementia: community care for the elderly mentally infirm. Beckenham: Croom Helm, 1984.

21 Carpenter GI, Demopoulus GR. Screening the elderly in the community: controlled trial of dependency surveillance using a questionnaire administered by volunteers. BMF 1990;300:1253-6.

(Accepted 6 February 1991 )
Institute of Child Health, University of Bristol, Bristol BS2 8BJ

Karen Thorpe, PHD, research psychologist

Jean Golding, PHD, reader in child health

Rosemary Greenwood, MSC, research assistant

University of Aberdeen, Aberdeen

Ian MacGillivray, $\mathrm{MD}$ emeritus professor of obstetrics and gynaecology

Correspondence to: $\mathrm{Dr}$ Thorpe.

BMf 1991;302:875-8

\title{
Comparison of prevalence of depression in mothers of twins and mothers of singletons
}

\author{
Karen Thorpe, Jean Golding, Ian MacGillivray, Rosemary Greenwood
}

\begin{abstract}
Objective-To determine whether the apparent additional and exceptional stresses associated with bearing and parenting twins affect the emotional wellbeing of mothers.

Setting-Great Britain, 1970-5.

Design-Cohort study of 13135 children born between 4 April and 11 April 1970. Mothers of all children, both singletons and twins, were interviewed by health visitors (providing demographic data) and completed a self report measure of emotional wellbeing (the Rutter malaise inventory) when the child was 5 years of age. The malaise scores of mothers of twins were compared with those of all mothers of singletons and then with those of mothers categorised by the age spacing of their children (only one child, widely spaced, or closely spaced), taking account of maternal age, social class, and whether the study child had a disability, by using logistic regression.
\end{abstract}

Subjects-139 mothers of twins-122 pairs of twins and 17 twins whose cotwin had died-and 12573 controls, who were mothers of singletons.

Results - A significantly higher proportion of mothers of twins at 5 years had malaise scores indicative of depression than mothers of singletons at the same age. Mothers who had borne twins, one of whom had subsequently died, had the highest malaise scores and were three times more likely than mothers of singletons to experience depression. Both mothers of twin pairs and mothers of singletons closely spaced in age were at significantly higher risk of experiencing depression than mothers of children widely spaced in age or mothers of only one child $(p<0.0001)$. Odds ratios indicated that the risk of depression in mothers of twins was higher than that in mothers of closely spaced singletons.

Conclusion-Mothers of twins are more likely to experience depression. This suggests a relation between the additional and exceptional stresses that twins present and the mother's emotional wellbeing.

\section{Introduction}

The role of stressors in increasing vulnerability to depression is well recorded. Life events (for example, death, illness, and separation) and stressful life circumstances (such as poverty, unemployment, disability, and marital discord) have been shown to be associated with the onset and maintenance of depressive states. ${ }^{1-7}$ Among mothers, additionally, serious doubts about having the child, ${ }^{8}$ obstetric problems, ${ }^{9}$ and characteristics of the infant ${ }^{111}$ have been found to relate to the onset of depression.

Mothers of twins are particularly likely to be vulnerable to depression. The birth, pregnancy, and care of twins presents a series of life events and circumstances that are somewhat different from and typically more stressful than those experienced by mothers of singletons. Greater psychological conflict among mothers expecting a multiple birth has been documented. In addition to the feelings of ambivalence experienced by most mothers on confirmation of their pregnancy, ${ }^{12}$ these mothers experience conflicts relating to the extra financial, care, and health burdens of bearing twins. ${ }^{13-16}$ Though a sense of pride in being "exceptional" is often reported by these mothers, ambivalence, shock, depression, and anger on learning of a multiple pregnancy have been found to be universal. ${ }^{16-18}$

For mothers of twins the pregnancy may be more physically and emotionally stressful than a singleton pregnancy. Bodily discomfort is exacerbated, with greater feelings of heaviness occurring at an earlier stage in pregnancy. Increased risk of obstetric problems such as preterm labour, fetal growth retardation, and proteinuric pre-eclampsia are associated with multiple births, ${ }^{15}+9.22$ and as a consequence more frequent monitoring of the mother and fetus and obstetric interventions are likely. Though the impact of obstetric interventions on the emotional wellbeing of the mother has not been widely investigated, recent studies suggest that some interventions raise anxiety. ${ }^{23}$

Associated with the increased obstetric risk is a poorer outcome of twin pregnancies with regard to admission to special care, congenital abnormalities, and perinatal mortality. ${ }^{24}$ These are all great sources of stress that have long lasting effects on the parent. The death of one of the twins, in particular, has been found to have a long term impact. on the emotional wellbeing of the mother. ${ }^{19} 25$

Though there are few systematic studies, the financial and care burden associated with twins is commonly identified as a source of stress. In the early months there may be difficulties in coping with the often unsynchronised sleeping, feeding, and crying patterns of the two infants; fatigue and exhaustion are common. The logistics of taking two young children out often means that the mother remains at home, and this results in her isolation. ${ }^{26}{ }^{27}$ Feeling of guilt associated with the mother's inability to give adequate and equal attention to both children are also common. ${ }^{1315212829}$ These feelings are further exacerbated if there are other children who also demand the mother's attention and care. ${ }^{15}$ The incidence of child abuse has been found to be raised in families of twins, perhaps reflecting these stresses. ${ }^{1723}$ There is some suggestion, too, that the advent of twins may place a strain on the marital relationship. ${ }^{\text {is }}$ 
Two studies have associated multiple birth with the emotional wellbeing of the mother. Powell conducted a study of 61 mothers of first born twins. ${ }^{29} \mathrm{He}$ found that in the first year of motherhood these mothers reported more symptoms of stress characterised by a predominance of anxiety and fatigue than matched controls, who were mothers of singletons. Haigh and Wilkinson ${ }^{27}$ in a study of 84 sets of twins found no differences in scores on the Leeds anxiety and depression questionnaire ${ }^{30}$ between mothers of twins and random or matched controls at three weeks post partum. Subsequent measures at three and six months post partum, however, disclosed a trend in which the proportion of mothers of twins experiencing depression and anxiety increased while that of controls decreased. They suggest that the stress experienced by mothers of twins is related to the number of children for whom the mother has to care rather than to the twinning itself. Neither this study nor that of Powell, however, assessed the independent effects of twinning with other stress factors statistically controlled. In the present study we analysed the 1970 child health and education study birth cohort, in which information on emotional wellbeing was available for 139 mothers of twins: 122 pairs of twins and 17 twins whose cotwin had died. ${ }^{31}$ We used multivariate analyses to assess the independent effect of twinning and other pertinent factors on the emotional wellbeing of the mother.

\section{Methods}

Information concerning 13135 (80\%) of surviving children from the birth cohort of the child health and education study was collected at the age of 5 years. ${ }^{31}$ A rate of attrition of $20 \%$ was due to failure to trace the children $(13 \%)$ and non-response $(7 \%)$. The mother was asked to complete a questionnaire, which included the 24 item Rutter malaise scale. ${ }^{34}$ This asked the mother to indicate the presence or absence of several symptoms of mood and psychosomatic disorder. The maximum possible score was thus 24 and the minimum zero. The scale is based on the 196 item Cornell medical index of health questionnaire, ${ }^{35}$ which has been found to be a satisfactory predictor of emotional disturbance in adults. On the malaise scale a score of $\geqslant 7$ is predictive of clinical depression. ${ }^{3+37}$ We therefore examined the malaise score as a dichotomous variable with a cut off point of $>6$. Other variables used in the analyses were: the mother's age at the birth of the study child or children (under 20,20-24, 25-29, or $\geqslant 30$ ); number of other children living in the household (none, one, two, or three or more); social class based on the occupation of the father figure resident in the household by the registrar general's classification of
1970 (non-manual I, II, or III, manual III or IV/V, or no father figure present); child's state of health (no handicap or disability, or minor disability, or moderate or severe disability); status of the study child or children (singleton, twin pair, or twin whose cotwin died); and family status of child or children (only child, child with widely spaced sibling(s) ( $\geqslant 2$ years), child with closely spaced sibling(s) ( $<2$ years), or a twin pair).

Statistical methods-For analysis of the malaise score we entered the variables of interest into a logistic regression analysis by using the biomedical programs data package. In the case of the disability variable mothers of pairs of twins were attributed the highest disability score from either of the pair. In one of two series of analyses the independent variables relating to the number of children in the household and the birth status of the study child or children were entered; in the other the variable relating to spacing of children's ages was used. The three variables could not be entered into the same regression because they represented different but largely overlapping means of explaining the variation. The first analysis pertains to the effect of twinning itself and includes those mothers who had borne twins, of whom one had died, as a separate group, while the second pertains to child care burden associated with spacing of children, with pairs of twins representing the closest spacing group, and excludes mothers of a twin without a cotwin.

\section{Results}

Table I shows the unadjusted relations between malaise scores and independent variables for mothers of both twins and singletons. Strong trends, in which the proportion of mothers with malaise scores $>6$ increased with lower social class, a larger number of children in the household, and presence of disability in the study child, were evident in mothers of singletons. In mothers of twins the trends were less reliable owing to smaller numbers. The youngest group of mothers of singletons, all of whom were aged less than 20 at the birth of the study child, had a considerably higher proportion of scores indicative of depression than any other age group. Table II shows that mothers of twins were more likely to be depressed than mothers of singletons (proportions with score $>6,23.9 \%$ and $34 \cdot 4 \%$ respectively), and those women who had borne twins, one of whom had died, had a still higher proportion with malaise scores above the threshold indicative of depression $(52.9 \%)$. A trend in which malaise scores increased with closer age spacing between children was also evident.

Tables III and IV give the results of the logistic regressions. In these analyses all variables entered were

TABLE I-Median (range) malaise scores and proportion with scores $>6$ by maternal variables for mothers of twins and singletons

\begin{tabular}{|c|c|c|c|c|c|c|}
\hline \multirow[b]{2}{*}{ Variable } & \multicolumn{3}{|c|}{ Singletons } & \multicolumn{3}{|c|}{ Twins } \\
\hline & No of mothers ${ }^{\star}$ & $\begin{array}{l}\text { Median (interquartile } \\
\text { range) score }\end{array}$ & $\begin{array}{c}\text { Proportion }(\%) \text { with } \\
\text { score }>6\end{array}$ & No of mothers $\dagger$ & $\begin{array}{l}\text { Median (interquartile } \\
\text { range) score }\end{array}$ & $\begin{array}{c}\text { Proportion }(\%) \text { with } \\
\text { score }>6\end{array}$ \\
\hline \multicolumn{7}{|l|}{ Maternal age: } \\
\hline$<20$ & 1079 & $5(3-8)$ & $35 \cdot 1$ & 4 & $5(3-6)$ & $25 \cdot 0$ \\
\hline $20-24$ & 4478 & $4(2-6)$ & $23 \cdot 9$ & 36 & $4(3-7)$ & $33 \cdot 3$ \\
\hline $25-29$ & 3915 & $3(1-6)$ & $21 \cdot 0$ & 47 & $5(2-9)$ & $38 \cdot 3$ \\
\hline$\geqslant 30$ & 2958 & $4(2-6)$ & $23 \cdot 4$ & 35 & $3(2-8)$ & $31 \cdot 4$ \\
\hline \multicolumn{7}{|l|}{ Social class of partner: } \\
\hline Non-manual & 4196 & $3(1-5)$ & $14 \cdot 7$ & 37 & $4(2-7)$ & $32 \cdot 4$ \\
\hline III manual & 5535 & $4(2-7)$ & $26 \cdot 0$ & 54 & $5(3-9)$ & $38 \cdot 9$ \\
\hline$I V$ and $V$ & 2159 & $4(2-8)$ & $31 \cdot 5$ & 26 & $3(2-6)$ & $23 \cdot 1$ \\
\hline No partner & 636 & $5(2-9)$ & $39 \cdot 9$ & 5 & $7(4-13)$ & $60 \cdot 0$ \\
\hline \multicolumn{7}{|c|}{ No of other children in household: } \\
\hline 0 & 1307 & $4(2-6)$ & $22 \cdot 5$ & 28 & $4(2-7)$ & $28 \cdot 6$ \\
\hline 1 & 6216 & $3(1-6)$ & $20 \cdot 3$ & 36 & $4(2-8)$ & $33 \cdot 3$ \\
\hline 2 & 3092 & $4(2-7)$ & $22 \cdot 5$ & 34 & $4(2-7)$ & $32 \cdot 4$ \\
\hline$\geqslant 3$ & 1956 & $5(2-8)$ & $33 \cdot 3$ & 24 & $6(3-8)$ & $45 \cdot 8$ \\
\hline \multicolumn{7}{|l|}{ Disability in study child: } \\
\hline None & 11129 & $4(2-6)$ & $23 \cdot 0$ & 100 & $4(2-8)$ & $35 \cdot 0$ \\
\hline Minor & 382 & $4(2-7)$ & $32 \cdot 8$ & 8 & $2(1-6)$ & $25 \cdot 0$ \\
\hline Moderate to severe & 423 & $5(2-8)$ & $36 \cdot 7$ & 11 & $5(2-7)$ & $27 \cdot 3$ \\
\hline
\end{tabular}

^Data were missing for some mothers for each variable.

tData on disability were missing for three mothers. 
TABLE II-Median (range) malaise scores and proportion of scores $>6$ for all mothers by birth status and family status of study child or children

\begin{tabular}{lccc}
\hline Variable & No of mothers & $\begin{array}{c}\text { Median (interquartile } \\
\text { range) score }\end{array}$ & $\begin{array}{c}\text { Proportion }(\%) \text { with } \\
\text { score }>6\end{array}$ \\
\hline Status of study child or children: & & & \\
$\quad$ Singleton & 12573 & $4(2-6)$ & $23 \cdot 9$ \\
$\quad$ One of a twin pair & 122 & $4(2-8)$ & $34 \cdot 4$ \\
$\quad$ Twin whose cotwin died & 17 & $7(1-9)$ & $52 \cdot 9$ \\
Family status`: & 1307 & $4(2-6)$ & $22 \cdot 5$ \\
$\quad$ Only child & 8608 & $3(2-6)$ & $22 \cdot 5$ \\
$\quad$ With widely spaced sibling(s) & 2656 & $4(2-7)$ & $28 \cdot 8$ \\
$\quad$ With closely spaced'sibling(s) & 122 & $4(2-8)$ & $34 \cdot 4$ \\
Twin pair & & & \\
\hline
\end{tabular}

^Data were missing for some mothers.

TABLE III-Results of logistic regression analysis on proportions of malaise scores $>6$ for all mothers $(n=11889)$ with number of children in household and birth status of study child or children as independent variables

\begin{tabular}{|c|c|c|c|}
\hline Variable & Odds ratio & $\begin{array}{l}95 \% \text { Confidence } \\
\text { interval }\end{array}$ & $\chi^{2}$ \\
\hline \multicolumn{4}{|l|}{ Maternal age: } \\
\hline$<20$ & 1.8 & $1 \cdot 5$ to $2 \cdot 0$ & \\
\hline $20-24$ & $1 \cdot 1$ & $1 \cdot 0$ to $1 \cdot 2$ & \\
\hline $25-29 \dagger$ & $1 \cdot 0$ & & \\
\hline$\geqslant 30$ & $1 \cdot 0$ & 0.9 to $1 \cdot 1$ & $51 \cdot 1^{\star}$ \\
\hline \multicolumn{4}{|l|}{ Social class of partner: } \\
\hline Non-manual $†$ & $1 \cdot 0$ & & \\
\hline III manual & $1 \cdot 8$ & $1 \cdot 6$ to $2 \cdot 0$ & \\
\hline IV and $\mathrm{V}$ & $2 \cdot 2$ & $2 \cdot 0$ to $2 \cdot 5$ & \\
\hline No partner & $3 \cdot 2$ & $2 \cdot 6$ to $3 \cdot 8$ & $223 \cdot 17^{\star}$ \\
\hline \multicolumn{4}{|c|}{ No of other children in household: } \\
\hline $0 \dagger$ & $1 \cdot 0$ & & \\
\hline 1 & $1 \cdot 0$ & 0.9 to $1 \cdot 2$ & \\
\hline 2 & $1 \cdot 3$ & $1 \cdot 1$ to 1.5 & \\
\hline$\geqslant 3$ & 1.7 & $1 \cdot 5$ to $2 \cdot 1$ & $83 \cdot 6^{\star}$ \\
\hline \multicolumn{4}{|l|}{ Disability in study child: } \\
\hline Nonet & $1 \cdot 0$ & & \\
\hline Minor & $1 \cdot 6$ & $1 \cdot 3$ to $2 \cdot 0$ & \\
\hline Moderate to severe & $1 \cdot 7$ & $1 \cdot 3$ to $2 \cdot 0$ & $35 \cdot 8^{\star}$ \\
\hline \multicolumn{4}{|c|}{ Status of study child or children: } \\
\hline Singletont & $1 \cdot 0$ & & \\
\hline Twin pair & $1 \cdot 6$ & $1 \cdot 1$ to $2 \cdot 3$ & \\
\hline Twin whose cotwin died & $3 \cdot 0$ & $1 \cdot 1$ to $8 \cdot 1$ & $9 \cdot 0^{\star \star}$ \\
\hline
\end{tabular}

TABLE IV-Results of logistic regression on proportions with malaise scores of $>6$ for mothers of twins and singletons $(n=11872)$ with family status of study child or children as independent variable

\begin{tabular}{|c|c|c|c|}
\hline Variable & Odds ratio & $\begin{array}{c}95 \% \text { Confidence } \\
\text { interval }\end{array}$ & $\gamma^{2}$ \\
\hline \multicolumn{4}{|l|}{ Maternal age: } \\
\hline$<20$ & 1.5 & 1.3 to 1.8 & \\
\hline $20-24$ & $1 \cdot 0$ & 0.9 to 1.2 & \\
\hline $25-29+$ & 1.0 & & \\
\hline$\geqslant 30$ & $1 \cdot 1$ & $1 \cdot 0$ to $1 \cdot 2$ & $30 \cdot 7^{\star}$ \\
\hline \multicolumn{4}{|l|}{ Social class of partner: } \\
\hline Non-manual $\dagger$ & 1.0 & & \\
\hline III manual & 1.9 & $1 \cdot 7$ to $2 \cdot 1$ & \\
\hline IV and $\mathrm{V}$ & $2 \cdot 4$ & $2 \cdot 8$ to $4 \cdot 2$ & \\
\hline No partner & $3 \cdot 5$ & $2 \cdot 8$ to $4 \cdot 2$ & $279 \cdot 3^{\star}$ \\
\hline \multicolumn{4}{|l|}{ Disability in study child: } \\
\hline Nonef & $1 \cdot 0$ & & \\
\hline Minor & 1.6 & $1 \cdot 3$ to $2 \cdot 0$ & \\
\hline Moderate to severe & $1 \cdot 7$ & $1 \cdot 3$ to $2 \cdot 1$ & $37 \cdot 8^{\star}$ \\
\hline \multicolumn{4}{|l|}{ Family status: } \\
\hline Only child $\dagger$ & $1 \cdot 0$ & & \\
\hline With widely spaced sibling(s) & $1 \cdot 1$ & 0.97 to 1.3 & \\
\hline With closely spaced sibling(s) & 1.4 & $1 \cdot 2$ to $1 \cdot 6$ & \\
\hline Twin pair & 1.8 & $1 \cdot 3$ to $2 \cdot 0$ & $22 \cdot 5^{\star}$ \\
\hline
\end{tabular}

${ }^{\star} \mathrm{p}<0.0001$.

tReference group.

Mothers of twins, one of whom had died $(\mathrm{n}=17)$ are excluded from the analysis.

found to predict depression (maternal malaise score $>6$ ). Maternal youth, social class (particularly being an unsupported mother), number of children in the household, and disability in the study child were all found to predict independently high maternal malaise.

Independent of these variables, presence of a twin was found to be predictive of depression (table III); mothers who had borne twins, one of whom had died, were particularly vulnerable-odds ratios indicated that these mothers were three times more likely to experience depression than mothers of singletons. In the second analysis (table IV), in which the family status of the study child or children was the variable, mothers of pairs of twins were significantly more depressed than mothers of widely spaced singletons or only one child. Odds ratios indicated an inverse linear relation between the age spacing of children and incidence of depression. In comparison with mothers with closely spaced children, mothers of twins were even more likely to experience depression, though this finding was not significant.

\section{Discussion}

Our results suggest that the emotional wellbeing of mothers of twins was poor relative to that of mothers of singletons. This effect was independent of social factors (social class and being without a partner); demographic factors (maternal age and number of children in the household); and the presence of disability in either child, though there is a greater risk of disability among twins.

One explanation for the raised malaise scores among mothers of twins is the greater childcare burden twins present to the parent. Indeed, this is the most common contention in published work on twins. Our data provide support for these conjectures. The number of children in the household, closer age spacing between children, and twinning were all associated with maternal malaise. These associations were, however, mutually independent. Thus the conclusion drawn by Haigh and Wilkinson that it is the number of children and not twinning that is the scource of stress to the mother $^{27}$ is not supported in the present paper. The factor that emerged as important in our anlyses was the age spacing between children. Both mothers of closely spaced singletons and mothers of twins were at significantly greater risk of depression. The impact was greatest for mothers of twins. It would seem that the care burden of twins and closely spaced siblings is independent of the number of children. The simultaneous demands of two children, the difficulties of mobility, and, possibly, the additional financial burden they pose are stresses shared by mothers of twins and closely spaced siblings.

Death of an infant and the bereavement that follows are unique in the case of twins. ${ }^{1925}$ When there is a surviving twin the mother has both the demands of a baby during bereavement and a reminder of the baby she has lost. ${ }^{25}$ Additionally, as the mother still has a baby the need for sympathy and support may not be perceived by others. ${ }^{2125}$ In our study mothers who had lost one twin had the highest malaise scores five years after the birth. As mothers who had lost a singleton or both twins were not followed up we do not have comparative data on their emotional wellbeing.

Several studies have found a raised incidence of child abuse in families with twins. ${ }^{17233}$ Groothuis et al suggest that this is a reflection of the extreme stresses faced by families of twins and call for specific preparation of parents expecting a multiple birth and for follow up support. ${ }^{17}$ Our findings also suggest the need for specific antenatal preparation and greater awareness and support on the part of health workers both before and after the birth; they also indicate clearly that a mother who experiences the death of one twin has special needs.

1 Paykel ES, Myers JK, Dienelt MN, Klerman GL, Lindenthal JJ, Pepper MP. Life events and depression: a controlled study. Arch Gen Psychiatry 1969;21:753-60.

2 Paykel EW. Recent life events in the development of depressive disorders. In Depue $\mathrm{R}$, ed. The psychobiology of the depressive disorder. New York Academic Press, 1979:245-62.

3 Brown GW, Harris T. The social origins of depression: a study of psychiutric disorder in women. London: Tavistock, 1978.

4 Costello CG. Social factors associated with depression: a retrospective community study. Psychol Med 1982;12:329-39.

5 Henderson S, Duncan-Jones P, Byrne DG, Scott R, Adcocks S. Psychiatric disorder in Canberra. Acta Psychiatr Scand 1979;60:355-74 
6 Bebbington PE, Sturt E, Tennant C, Hurry J. Misfortune and resilience: a communits studs of women. Psychol hed 1984;14:347-63.

7 Hammen $C$. Depression and cognition about stressful life events. In Allov LB, ed Cognutre processes in depression. New York: Guildford Press, 1988 .

8 Kumar R, Rubson KM A prospective study of emotional disorders in childbearing women. Brf Psychiatry 1984;144:35-47.

O'Hara MW. Social support, life events and depression during pregnancy and the puerperium. Arch Gen Psychiatry 1986:43:569-73.

10 Trowell J. Possible effects of emergency caesarian section on the mother-child relationship. Early Hum Dev 1982;7:41-5

11 Grossman FK, Eichler LS, Winnickoff SA. Pregnancy, birth and parenthood: adaptation of mothers, fathers and infants. San Francisco: Jossey-Bass, 1980

12 Zajicek E. The experience of being pregnant. In: Wolkind S, Zajicek E, eds. Pregnancy: a psychological and social study. New York: Grune Stratton Academic Press, 198

3 Spillman JR. Emotional aspects of experiencing a multiple birth. Midwife, Health Visitor and Community Nurse 1987;23:54.

14 Spillman JR. Double exposure-coping with newborn twins at home. Midwife, Health Visitor and Community Nurse' 1984:20:92.

15 Sandbank AC. The effect of twins on family relationships. Acta Genet Med Gemellol (Roma) 1988:37:161-71

16 Scheinfield A. Twins and supertwins. Harmondsworth: Penguin, 1973.

17 Groothuis JR, Altemeier WA, Robarge JP, et al. Increased child abuse in fathilies with twins. Pediatrics 1982:70:769-73.

18 Goshen Gottstein ER. The mothering of twins, triplets and quadruplets. Psychiatry 1980;43:189-203.

19 Bryan EM. The loss of a twin. Maternal and Child Health 1983;May:201-6.

20 Freidrich L, Rowland C. The twins handbook. London: Robins, 1983.

1 Linney J. Multiple births. London: Routledge and Kegan Paul, 1983.

22 MacGillivray I, Campbell DM. Management of twin pregnancies. In: MacGillivray I, Campbell DM, Thompson B, eds. Twinning and twin Chichester: Wiley, 1988

23 Green J. Calming of harming? A critical review of psychological effects of fetal diagnosis of pregnant women. London: Galton Institute, March 1990. Occasional papers, second series, No 2.

24 Magnus P, Arntzen A, Samuelson SO, Halderson T, Bakketeig T. No correlation in post-neonatal deaths for twins. A study of the early mortality of twins based on the Norwegian medical birth registry. Early Hum Dev 1990;22:89-97.

25 Lewis E, Bryan EM. Management of perinatal loss of a twin. BMJ 1988:297:1321-2.

26 Dell'Avvocato L. Do we realise the stress caused by twins? Health Visitor 1988;61:37

27 Haigh J, Wilkinson L. Care and management of twins. Health Visitor 1989;62:43-5

28 Robin M, Josse D, Tourette C. Mother-twin interaction during early childhood. Acta Genet Med Gemellol (Roma) 1988;37:151-9.

29 Powell TJ. Symptoms of postnatal (atypical) depression in mothers of twins [MSc thesis] Surrey: Surrey University, 1981

30 Snaith RP, Bridge GWK, Hamilton M. The Leeds scales for the self assessment of anxiety and depression. Br f Psychiatry 1976;128:156-65.

31 Butler NR, Golding J. From birth to five: a study of health and behaviour of Britain's five veur olds. Oxford: Pergamon Press, 1986.

32 Nelson MHB, Martin CA. Increased child abuse in twins. Child Abuse and Neglect. 1985;9:501-5.

33 Tanimura M, Matsui I, Kobayashi N. Child abuse in one of a pair of twins in Japan. Lancet 1990;336:1298-9.

34 Rutter M, Tizard J, Whitmore K. Education, health and behaviour. London: Longman, 1980.

35 Brodman K, Erdmann AJ, Lorge I, Wolff HG, Broadbent TH. Cornell medical index: an adjunct to medical interview. FAMA 1949;140:530-4

36 Richman N. Depression in mothers of young children. $\mathcal{F} R$ Soc Med 1978;71:489-93.

37 Rutter M, Tizard J, Yule W, Graham P, Whitmore K. Isle of Wight Studies 1964-1974. Psychol Med 1976;6:313-32.

(Accepted 6 February 1991)

\title{
Routine examination in the neonatal period
}

\author{
G D Moss, P H T Cartlidge, B D Speidel, T L Chambers
}

Abstract

Objective-To assess the value of the second neonatal examination as a medical surveillance procedure.

Design-Prospective survey of routine neonatal examinations and the abnormalities identified during 8 March-30 June 1988.

Setting-Maternity unit with an annual birth rate of 5700 .

Subjects-For first neonatal examination: 1795 babies born in the unit during the $\mathbf{1 1 5}$ day observation period. For second routine examination: 1747 babies $(97 \cdot 3 \%)$ discharged from postnatal ward.

Main outcome measures-Missed abnormalities (present but not previously noted); minor abnormalities (superficial infection or trivial or transient abnormalities not requiring intervention); and important abnormalities (unlikely to have been present at first examination but requiring intervention).

Results-An abnormality was detected in 158 $(8.8 \%)$ infants on first neonatal examination. 1428 (79.6\%) babies had a routine second examination, which disclosed 63 previously undetected abnormalities. Of these, seven $(11 \%)$ would have been present on first examination, $49(78 \%)$ were considered minor, and seven (11\%) important - the most consequential being dislocatable hips (four infants). Thus an important finding was detected by only $0.5 \%$ of second examinations.

Conclusions - A second thorough examination in the early neonatal period cannot be justified as a screening procedure. A repeat examination of the hips alone in the first week of life is necessary.

\section{Introduction}

The report of the Joint Working Party on Child Health Surveillance ${ }^{1}$ suggests that each neonate should receive a thorough physical examination within 24 hours after birth with a repeat examination of the hips on discharge from hospital or within 10 days after birth but no further routine examination until the age of 6 weeks. This contrasts with previous guidelines, which recommended a second full examination, before discharge, for all those babies remaining in hospital for more than two or three days. ${ }^{2}$ The value of an initial neonatal examination is widely accepted, but there is little information concerning the previously recommended second neonatal examination to either support or refute its exclusion from the core programme for child health surveillance proposed by the Hall report.

We recently reviewed the practice of routine neonatal examinations within our maternity unit. We present our results with particular reference to the second neonatal examination to provide information on its value as a medical surveillance procedure.

\section{Subjects and methods}

Details of the routine examinations of neonates performed by our senior house officers were collected prospectively from the case notes of all the 1795 babies born during 115 days from 8 March to 30 June 1988. These case notes were already being routinely scrutinised by the registrar so it was therefore possible to collect data without drawing the attention of the senior house officers to the study. The policy of the unit was that babies were fully examined within 24 hours after birth and again on the day of discharge. The second examination was omitted only in those babies discharged within 18 hours after birth and in some babies discharged at a weekend, provided that they had received a full examination in the 24 hours before going home.

All abnormalities identified were recorded. Unfortunately, we were unable to ascertain from the case notes whether parents or nursing or medical staff were the first to discover the abnormality. Any abnormalities detected on the second examination which had not been previously noted were classified as: missed abnormalities - that is, those that would have been present but were not previously noted; minor abnormalities-that is, superficial infection or trivial or
Correspondence to: Dr Moss.

BMf 1991;302:878-9 